\title{
Materials Selection for Oxide-based Resistive Random Access Memories
}

\author{
Yuzheng Guo and John Robertson
}

\author{
Engineering Dept, Cambridge University, Cambridge CB2 1PZ, UK.
}

\begin{abstract}
The energies of atomic processes in resistive random access memories (RRAM) are calculated for four typical oxides, $\mathrm{HfO}_{2}, \mathrm{TiO}_{2}, \mathrm{Ta}_{2} \mathrm{O}_{5}$ and $\mathrm{Al}_{2} \mathrm{O}_{3}$, to define a materials selection process. $\mathrm{O}$ vacancies have the lowest defect formation energy in the $\mathrm{O}$-poor limit, and dominate the processes. A band diagram defines the operating Fermi energy and $\mathrm{O}$ chemical potential range. It is shown how the scavenger metal can be used to vary the $\mathrm{O}$ vacancy formation energy, via the $\mathrm{O}$ chemical potential, and the mean Fermi energy. The high endurance of $\mathrm{Ta}_{2} \mathrm{O}_{5}$ RRAM is related to its more stable amorphous phase and adaptive lattice rearrangements of its $\mathrm{O}$ vacancy.
\end{abstract}

Resistive random access memory (RRAM) is becoming a main challenger non-volatile memory technology to Flash memory. However, a wide range of material systems are presently being studied, which use various different switching mechanisms. There has been great intellectual curiosity that so many different systems can undergo switching [1-8]. A working technology should be compatible with CMOS process technology, which favors using oxide materials due to their greater thermal stability and their likely larger resistance contrast between their low resistance state (LRS) and high resistance state (HRS). However, developing a working technology also requires materials selection, so that effort is focused on the most useful materials rather than dissipated over too many. Materials selection requires us to understand which material properties control each aspect of device performance, such as switching speed, resistance window, retention time and endurance (switching cycles). To date, there have been various models of the switching mechanism, some more detailed than others [1-23]. There are also compact electrical models such as the 'hourglass' model [14-15], as well as models of noise, the variability of switching parameters [5,7] and ultimate scalability [23]. On the other hand, there have not been fewer materials-based models. When high $\mathrm{K}$ oxides replaced $\mathrm{SiO}_{2}$ as a gate oxide, materials selection identified that the heat of reaction of the oxide with $\mathrm{Si}$ and its band offsets to $\mathrm{Si}$ were the two key factors [24-26]. A similar analysis has yet to be achieved for RRAM materials.

Here, we focus on RRAMs based on the wide band gap metal oxides such as $\mathrm{HfO}_{2}, \mathrm{TiO}_{2}, \mathrm{Ta}_{2} \mathrm{O}_{5}$ and $\mathrm{Al}_{2} \mathrm{O}_{3}$. From high resolution transmission electron microscopy (HRTEM) and electron energy loss spectroscopy (EELS) measurements [6,8-10,13], the switching mechanism is believed to involve the formation of a conductive filament of oxygen vacancies across the oxide thin film. However, there is still limited understanding of the energetics of the relevant atomic processes involved for materials selection $[4,18]$. Here, we calculate the defect formation energies, migration barriers and electrical energy levels of the oxygen vacancies and interstitials in four key oxides used for RRAM; $\mathrm{HfO}_{2}, \mathrm{TiO}_{2}, \mathrm{Ta}_{2} \mathrm{O}_{5}$ and $\mathrm{Al}_{2} \mathrm{O}_{3}$, so as to understand which properties are critical for memory operation.

An oxide-based RRAM consists of an oxide layer between two electrodes and with a thin metal layer next to one electrode that scavenges oxygen from the oxide to form $\mathrm{O}$ vacancies. This scavenging metal can differ from the metal in the oxide. Switching is initiated by a forming step, during which the oxygen vacancies coalesce into a filament between the electrodes, Fig 1(a). Various experiments have shown that oxygen vacancies are the mobile species in these systems 
[16], and calculations support this, as discussed shortly.

The temperature coefficient of resistance of the LRS determines if the filament is metallic or semiconducting. The data of Bao [27] suggests that it is metallic. The metallic condition sets the minimum density of vacancies (n) in the filament, from Mott's criterion [28-30] for the metalinsulator transition, as $n^{1 / 3}=1 / a_{H}$. Here, $a_{H}$ is the Bohr radius of the vacancy wavefunction, which can be calculated for that oxide. This criterion is more general than considering vacancy-vacancy interactions as in other approaches [19-22]. The forming process creates vacancies and assembles them into the filament. This occurs by drift of charged vacancies, aided by the field-enhancement around the tip of the growing filament (Fig 1e). Once the charged vacancies have entered the metallic filament, they are no longer subject to an electric field, so there is no force on them.

The SET and RESEST processes are shown in Figs 1(b-d). This shows how during reset to the HRS, the vacancies can either (b) move towards electrodes leaving a narrower filament, (c) disperse from the filament into the resistive bulk oxide, or (d) recombine with $\mathrm{O}$ interstitials. The hour glass model represents vacancies next to each electrode as two reservoirs [14]. In this model (b), the vacancies move from one reservoir to the other, conserving their number. On the other hand, in mechanisms (c) and (d) vacancies leave the reservoirs and then return. Their number may not be conserved from one cycle to another, unless exactly the same number of vacancies return to the filament [14].

To compare oxides, we calculated their electronic structures using the ab-initio plane wave pseudopotential method with the CASTEP code. Norm-conserving pseudopotentials are used with a plane wave cut-off of $780 \mathrm{eV}$. Due to the band gap error of density functional theory, the energy levels are calculated by the screened exchange hybrid functional [31]. The defect formation energies are calculated for each state using the supercell method [32-34].

The relative importance of the processes $(b, c, d)$ in Fig 1 can be estimated from the defect formation energies in their various charge states. To appreciate the factors involved, Fig 2(a) plots the formation energy of various defects in $\mathrm{HfO}_{2}$ against the Fermi energy $\left(\mathrm{E}_{\mathrm{F}}\right)$, in the standard Orich limit $\left(\mathrm{O}_{2}\right.$ at atmospheric pressure, $\left.\mu_{\mathrm{O}}=0 \mathrm{eV}\right)$, the condition used in many simulations. Here, $\mu_{\mathrm{O}}$ is the $\mathrm{O}$ chemical potential [32]. Fig 2(a) suggests that the $\mathrm{O}$ interstitial is the lowest cost defect in these conditions and would therefore be dominant [18]. This would be contrary to most empirical models. However, the metal electrodes or the presence of a metal scavenging layer in fact shifts $\mu_{O}$ of the film towards the $O$-poor limit, which is near $\mu_{\mathrm{O}}$ of the scavenging metal/oxide equilibrium. This is a key point. If $\mathrm{Hf}$ is the scavenging metal, this would lower $\mu_{\mathrm{O}}$ by a huge $5.9 \mathrm{eV}$ compared to $\mu_{\mathrm{O}}=0$. This reduces the $\mathrm{O}$ vacancy formation energy in its neutral state from $6.1 \mathrm{eV}$ to $0.2 \mathrm{eV}$, that is to nearly $0 \mathrm{eV}$ [32]. In contrast, the interstitial formation energy becomes very large, and this defect becomes irrelevant near equilibrium. The same effect occurs in the other three oxides of interest, as in Figs 2(c-e). Thus, the $\mathrm{O}$ chemical potential is the key system parameter.

The shaded areas of Figs 2(b-e) also show the relevant range of $\mathrm{E}_{\mathrm{F}}$ in the cell, which is controlled by the work functions of the relevant electrode metals. In each case, $\mathrm{O}$ vacancies now have very low formation energy (except for $\mathrm{Al}_{2} \mathrm{O}_{3}$ ). Table 1 also shows that the Frenkel (vacancy + interstitial) defect formation energy is large in all oxides. We also calculated the $\mathrm{O}$ migration energies, and found similar values for amorphous $\mathrm{HfO}_{2}$ to those of Clima [17]. Now, the 'hour-glass' model [14] proposed that the total number of $\mathrm{O}$ vacancies in the system stays roughly constant, otherwise the memory window would rapidly close with cycling [15]. Thus, from this and the large Frenkel energy, we can exclude $\mathrm{O}$ interstitials and process (d) from consideration.

We have assembled the data into band diagrams for each oxide as shown in Fig 3(a). This shows the band energies and defect levels aligned to the vacuum level. We can mark on Fig 3(a) the Fermi 
level of the oxide's parent metal. The metal work functions are taken from Michaelson [35]. For all but $\mathrm{HfO}_{2}, \mathrm{E}_{\mathrm{F}}$ lies near $-4.3 \mathrm{eV}$. The $\mathrm{O}$ vacancy is in its +2 charge state for $\mathrm{HfO}_{2}, \mathrm{Ta}_{2} \mathrm{O}_{5}$ and $\mathrm{TiO}_{2}$ for $\mathrm{E}_{\mathrm{F}}=-4.3 \mathrm{eV}$. It is in the $\mathrm{V}^{2-}$ configuration for $\mathrm{Al}_{2} \mathrm{O}_{3}$, and this makes its RRAM operation different.

We extend this analysis to allow scavenger metals to vary from the parent metal of the oxide. We first plot the heat of formation of bulk oxides versus the work function of the parent metal [36] in Fig 4(a). We then calculated the $\mathrm{O}$ vacancy formation energy, $\mathrm{E}_{\text {form }}$, for a number of metal oxides in their neutral configurations. These are plotted in Fig 4(b) for the O-rich condition. We see that $\mathrm{E}_{\text {form }}$ tends to equal the heat of formation per $\mathrm{O}$ atom of the bulk oxide. Now, the difference between the $\mathrm{E}_{\text {form }}$ in the O-rich and O-poor limits (ignoring any sub-stoichiometric oxides) equals the bulk heat of formation/O atom. Thus, we also plot $\mathrm{E}_{\text {form }}$ in the $O$-poor condition in Fig 4(b), where we see that it is close to $0 \mathrm{eV}$ for many oxides except for $\mathrm{Al}_{2} \mathrm{O}_{3}$. This is a valuable general result.

We noted earlier that the presence of a scavenger metal can be used to set $\mu_{\mathrm{O}}$. This occurs because the vacancy formation energy $E_{\text {form }}$ at any arbitrary oxygen chemical potential $\mu_{1}$ is given by,

$$
E_{\text {form }}\left(\mu_{1}\right)=E_{\text {form }}(0)+\mu_{1}
$$

where $E_{\text {form }}(0)$ is the vacancy formation energy at $\mu_{\mathrm{O}}=0 \mathrm{eV}$. We can increase $\mathrm{E}_{\text {form }}$ by raising $\mu_{\mathrm{O}}$ by using scavenging metals that are more electronegative than the parent metal, as in Fig 5. A larger $\mathrm{E}_{\text {form }}$ will then lower the possibility of forming new vacancies during switching cycles, so enforcing the constant vacancy numbers over switching cycles as in the hour glass model. This would prolong endurance.

The scavenging metal can also be used to set $\mathrm{E}_{\mathrm{F}}$ near that electrode, as in Fig 3(b). Without a scavenger metal, $\mathrm{E}_{\mathrm{F}}$ will lie at the work function of the electrode metal. With the parent metal electrode, $\mathrm{V}_{\mathrm{O}}$ will be in the $\mathrm{V}^{2+}$ state for $\mathrm{HfO}_{2}$ and $\mathrm{TiO}_{2}$ cases, but be in the neutral $\mathrm{V}^{0}$ state for $\mathrm{Ta}_{2} \mathrm{O}_{5}$ and as $\mathrm{V}^{-}$for $\mathrm{Al}_{2} \mathrm{O}_{3}$. It is useful for the $\mathrm{O}$ vacancy to be in the positive charge state, to ensure controlled drift under the switching field. $\mathrm{E}_{\mathrm{F}}$ can be lowered for this purpose in $\mathrm{Ta}_{2} \mathrm{O}_{5}$ by including a less electropositive scavenging layer, whose $\mathrm{E}_{\mathrm{F}}$ then lies slightly deeper below the vacuum level. Ensuring a charged defect might be used to increase switching speed, and endurance. (In assembling this diagram, we have assumed that the Schottky barrier pinning factor $\mathrm{S}$ of the oxides is $\mathrm{S}=1$, for simplicity [24]. The metal induced gap state (MIGS) model gives lower values [28], but explicit calculations show values closer to $S=1$ [37].) Thus, the inclusion of a scavenger metal can be used to control both vacancy concentration and its charge state.

Goux et al [15] have studied the effect of a Ta scavenging layer in $\mathrm{HfO}_{2}$ based devices. They found that the resistance window between HRS and LRS is reduced for a Ta scavenging layer. Zhuo et al [41] found that a Ge scavenger layer increased the endurance.

Now consider materials selection in general. $\mathrm{TiO}_{2}$ is less favored for endurance [13] because it possesses a number of sub-stoichiometric phases $\mathrm{TiO}_{2-\mathrm{x}}$ which will interfere with conservation of vacancy numbers. $\mathrm{HfO}_{2}, \mathrm{Ta}_{2} \mathrm{O}_{5}$ and $\mathrm{Al}_{2} \mathrm{O}_{3}$ do not have stable, insulating sub-stoichiometric oxides. $\mathrm{Al}_{2} \mathrm{O}_{3}$ has a comparatively large $\mathrm{O}$ vacancy formation energy, and a large migration barrier energy, so that vacancy migration in RRAM cycling would be impeded. Experimentally, $\mathrm{Ta}_{2} \mathrm{O}_{5}$ shows good endurance [4,12]. Crystalline $\mathrm{Ta}_{2} \mathrm{O}_{5}$ has a complex layered structure [38] which has only recently been explained in a simple model. It has three $\mathrm{O}$ vacancy sites, two intra-layer sites and one interlayer site. The 2-fold coordinated intralayer vacancy is the most stable vacancy, and this gives a $0 / 2+$ state at about $2.0 \mathrm{eV}$ above the valence band edge, near midgap [34]. The other vacancies are less stable in their neutral state, and give levels neaer the conduction band edge. Crystalline $\mathrm{Ta}_{2} \mathrm{O}_{5}$ has an unusual 'adaptive' lattice [40] so its vacancies migrate by shuffling rearrangements with low 
migration energies. On the other hand amorphous $\mathrm{Ta}_{2} \mathrm{O}_{5}$ is more complicated. We have created network models of amorphous $\mathrm{Ta}_{2} \mathrm{O}_{5}$ by molecular dynamics (Fig 6a). Disorder interferes with the adaptive rearrangements of the vacancy configurations occuring in crystalline $\mathrm{Ta}_{2} \mathrm{O}_{5}$. The vacancies behave somewhat more like defects in earlier models of crystalline $\mathrm{Ta}_{2} \mathrm{O}_{5}$ [39]. There is a range of $\mathrm{O}$ vacancy configurations. The most stable neutral vacancy still gives states near midgap. Fig 6(b) shows an example of this vacancy with a more localised vacancy state near midgap. Similar results were found by Xiao and Watanabe [40]. The calculated migration energy for vacancies varies from 0.3 to $1.0 \mathrm{eV}$ for particular vacancies (Table 1 ), so that an average migration energy of $\sim 1.0 \mathrm{eV}$ is typical, close to the experimental value [41] but much less than calculated by Ramprasad [39]. $V_{O}$ would be in the neutral state for Ta electrodes, but can be moved to the $2+$ state under fields or by a change of electrode to higher work function metals like TiN (work function $4.6 \mathrm{eV}$ ). Zhuo et al [42] found that more electronegative scavenging metals with higher work function will increase endurance. The long endurance and retention time of $\mathrm{Ta}_{2} \mathrm{O}_{5}$ RRAM $[4,12]$ may be due to various factors; the ability of $\mathrm{Ta}_{2} \mathrm{O}_{5}$ to remain amorphous to higher temperatures than $\mathrm{HfO}_{2}$, its adaptive lattice for easy defect migrations in any crystalline inclusions [13], and that the vacancy is in $\mathrm{V}^{2+}$ state for typical electrode materials such as TiN.

In summary, we used first principle methods to calculate the energetics of oxygen vacancy processes in resistive random access memories (RRAM) for four typical oxides, $\mathrm{HfO}_{2}$, $\mathrm{TiO}_{2}, \mathrm{Ta}_{2} \mathrm{O}_{5}$ and $\mathrm{Al}_{2} \mathrm{O}_{3}$ as a guide to materials selection. The $\mathrm{O}$ vacancy formation energy, charge states and migration barriers are calculated. A band diagram defines the operating Fermi energy and $\mathrm{O}$ chemical potential range. We have shown how a scavenger metal can be used to tune the $\mathrm{O}$ chemical potential and thus the $\mathrm{O}$ vacancy formation energy for higher endurance. The metal electrodes and scavenger metal can also be used to vary the $\mathrm{O}$ vacancy charge state, to ensure a $2+$ state, to maximize drift. The high endurance of $\mathrm{Ta}_{2} \mathrm{O}_{5}$ RRAM is related to its more stable amorphous phase and adaptive lattice rearrangements of its $\mathrm{O}$ vacancy. 


\section{References}

1. R Waser, M Aono, Nature Nano 6833 (2007); R Waser, R Dittmann, G Staikov, K Szot, Adv Mat 212632 (2009)

2. K M Kim, D S Jeong, C S Hwang, Nanotechnology 22254002 (2011); D S Jeong, R Thomas, R S Katiyar, J F Scott, H Kohlstedt, A Petraru, C S Hwang, Rep Prog Phys 750756502 (2012)

3. J J Yang, M D Pickett, X Li, D A A Ohlberg, D R Stewart, R S Williams, Nat Nanotech 3429 (2008)

4. M J Lee, C B Lee, D Lee, S R Lee, M Chang, J H Hur, Y B Kim, C J Kim, D H Seo, S Seo, U I Chung, I K Yoo, K Kim, Nature Mats 10625 (2011)

5. $\quad$ H S P Wong, H Y Lee, S M YU, Y S Chen, Y Wu, P S Chen, Proc IEEE 1001951 (2012)

6. D H Kwon, K M Kim, J H Jang, M Jeon, M H Lee, G H Kim, X S Li, G S Park, B Lee, S Han, M Kim, C S Hwang, Nat Nano 5148 (2010)

7. D Ielmini, F Nardi, C Cagli, Nanotechnology 22254022 (2011)

8. G Bersuker, D Gilmer, D Veksler, P Kirsch, L Vandelli, A Padovani, L Larcher, K McKenna, A Shluger, V Igesias, M Porti, M Nafria, J App Phys 110124518 (2011)

9. Z Wei, T Takagi, Y Katoh, T Ninomiya, K Kawai, S Mitani, K Katayama, S Fujii, R Miyanaga, Y Kawashima, T Mikawa, K Shimakawa, K Aono, Tech Digest IEDM (2011) 31.4

10. B Chen, Y Lu, Y H Fu, F F Zhang, P Huang, Y S Chen, L F Liu, X Y Liu, J F Kang, Y BY Wang, Z Fang, H Yu, et al, Tech Digest IEDM (2011) 12.3.

11. J P Strachan, M D Pickett, J J Yang, S Aloni, A L D Kilcoyne, G M Ribeiro, R S Williams, Adv Mat 223573 (2010); F Miao, J P Strachan, J J Yang, M X Zhang, I Goldfarb, A C Torrezan, P Eschbach, R D Kelley, G M Ribeiro, R S Williams, Adv Mat 235633 (2011); I Goldfarb, F Miao, J J Wang, W Yi, J P Strachan, M X Zhang, M D Pickett, G M Ribeiros, R S Williams, App Phys A 1071 (2012)

12. J J Yang, M X Zhang, J P Strachan, F Miao, M D Pickett, R D Kelley, G M Ribeiro, R S Williams, App Phys Lett 97232102 (2010)

13. J P Strachan, G M Riberio, J J Yang, M X Zhang, F Miao, I Goldfarb, M Holt, V Rose, R S Williams, App Phys Lett 98242114 (2011)

14. R Degraeve, L Goux, S Clima, B Govoreanu, Y Y Chen, M Jurczuk, G Groesenken, Tech Digest IEDM (IEEE, 2010) p 28.4, VLSI (2012) p75; IEDM (2011) p31.6; VLSI (2013) p98

15. L Goux, A Fantini, Y Y Chen, A Redolfi, R Degraeve, M Jurczuk, ECS Solid State Letts 3 Q79 (2014); Tech Digest VLSI (2014) p15.1.

16. L Goux,P Czarnecki, Y Y Chen, L Pantisano, D Wouters, App Phys Lett 97243509 (2010)

17. S Clima, Y Y Chen, R Degraeve, M Mees, K Sankaran, B Govoreanu, M Jurczak, S DeGendt, G Pourtois, App Phys Lett 100133102 (2012)

18. S Clima, K Sankaran, Y Y Chen, A Fantini, U Celano, A Belmonte, L Goux, B Govoreanu, R Degraeve, D J Wouters, M Jurczak, W Vandervorst, S DeGendt, G Pourtois, Phys Stat Sol RRL 8501 (2014)

19. B Magyari-Kope, S G Park, H D Lee, Y Nishi, J Mater Sci 477498 (2012)

20. K Kamiya, M Y Yang, S G Park, B M Kope, Y Nishi, M Niwa, K Shiraishi, App Phys Lett 100073502 (2012)

21. K H Xue, B Traore, P Blaise, L Fonseca, B DeSalvo, Y Nishii, IEEE Trans ED 611394 (2014)

22. K H Xue, P Blaise, L Fonseca, Y Nishii, Phys Rev Lett 110065502 (2013)

23. V V Zhirnov, R Meade, R K Cavin, G Sandhu, Nanotechnology 22254027 (2011)

24. J Robertson, J Vac Sci Technol B 181785 (2000) 
25. H J Hubbard, D G Schlom, J Mater Res 112757 (1996)

26. J Robertson, Rep Prog Phys 69327 (2006)

27. B Gao, J F Kang, Y S Chen, F F Zhang, B Chen, P Huang, L F Liu, X Y Liu, Y Y Wang, X A Tran, Z R Wang, H Y Yu, A Chin, Tech Digest IEDM (2011) p17.4

28. N F Mott, Proc Roy Soc A 3821 (1982)

29. P P Edwards, M J Sienko, Phys Rev B 172575 (1978)

30. J Robertson, R Gillen, Microelec Eng 109208 (2013)

31. K Xiong, J Robertson, M C Gibson, S J Clark, App Phys Lett 87183505 (2005)

32. J Robertson, S J Clark, Phys Rev B 83072505 (2011)

33. D Liu, S J Clark, J Robertson, App Phys Lett 96032905 (2010)

34. Y Guo, J Robertson, App Phys Lett 104112906 (2014)

35. H B Michaelson, J App Phys 484729 (1997)

36. J Robertson, O Sharia, A Demkov, App Phys Lett 91132912 (2007)

37. K Tse, J Robertson, Phys Rev Lett 99086805 (2007)

38. S H Lee, J Kim, S Kim, G Park, Phys Rev Lett 110232502 (2013)

39. R Ramprasad, J App Phys 945609 (2003); J App Phys 95954 (2004)

40. B Xiao, S Watanabe, Nanoscale 610169 (2014)

41. R Nakamura, T Toda, S Tsukui, M Tane, M Iswhimaru, T Suzuki, H Nakajima, J App Phys 116033504 (2014)

42. V Y Q Zhuo, Y Jiang, L P Shi, Y Yang, T C Chong, J Robertson, IEEE ED Lett 341130 (2013) 
Table 1. Parameter values for the four oxides. Bulk heat of formation, calculated vacancy formation energy in the $\mathrm{O}$-poor limit, $0 / 2+$ electrical transition energy (referred to vacuum level). Calculated $\mathrm{O}$ vacancy migration energy (in optimum charge state), Frenkel pair formation energy, work function of the parent metal.

\begin{tabular}{|l|l|l|l|l|l|l|}
\hline $\mathrm{eV}$ & $\mathrm{H}$ bulk & $\begin{array}{l}\mathrm{H}_{\text {vac }}\left(\mathrm{O}^{-}\right. \\
\text {poor limit) }\end{array}$ & $\mathrm{E}(0 / 2+)$ & $\Delta \mathrm{E}_{\text {mig }}$ & $\mathrm{H}_{\text {frenk }}$ & $\begin{array}{l}\text { Parent metal work } \\
\text { function }\end{array}$ \\
\hline $\mathrm{HfO}_{2}$ & -5.9 & 0.2 & -4.2 & 0.7 & 8.0 & 3.9 \\
\hline $\mathrm{TiO}_{2}$ & -4.8 & 0.5 & -4.3 & 0.7 & 6.1 & 4.3 \\
\hline $\mathrm{Ta}_{2} \mathrm{O}_{5}$ & -4.3 & 0.1 & -5.0 & $0.3-1.0$ & 4.0 & 4.25 \\
\hline $\mathrm{Al}_{2} \mathrm{O}_{3}$ & -6.8 & 1.5 & -5.8 & 1.7 & 12.1 & 4.28 \\
\hline
\end{tabular}


Figure captions

1. Schematic of the switching process. (a) low resistance state. (b) high resistance state (HRS), vacancies move toward electrode. (c) HRS and vacancies disperse into the insulating matrix, (d) HRS where vacancies recombine with $\mathrm{O}$ interstitials in the matrix. (e) Equipotential lines showing field enhancement around the metal tip of a growing filament. Diffusive drift of charged vacancies under the electric field.

2. (a) Defect formation energies of $\mathrm{HfO}_{2}$ in the O-rich limit. (b) defect formation energies of $\mathrm{HfO}_{2}$ in the O-poor limit at $\mu_{\mathrm{O}}=-5.9 \mathrm{eV}$, the $\mathrm{Hf} / \mathrm{HfO}_{2}$ equilibrium. (c) $\mathrm{O}$ vacancy and $\mathrm{O}$ interstitial formation energy for $\mathrm{TiO}_{2}$ in $\mathrm{O}$-poor limit. (d) $\mathrm{O}$ vacancy and $\mathrm{O}$ interstitial formation energy as a function of Fermi energy for $\mathrm{Ta}_{2} \mathrm{O}_{5}$. (e) $\mathrm{O}$ vacancy and $\mathrm{O}$ interstitial formation energy for amorphous $\mathrm{Al}_{2} \mathrm{O}_{3}$. Note the different behavior of vacancy in $\mathrm{Al}_{2} \mathrm{O}_{3}$.

3. (a) Combined band diagram for the oxides with energies referred to the vacuum level, showing band edges, $\mathrm{O}$ vacancy transition energies, and Fermi levels of the (parent) metal electrode. Al, Ti and Ta have similar work functions. (b) Band diagram for the oxides with different scavenger metals inserted, and how they can shift $\mathrm{E}_{\mathrm{f}}$ into the $\mathrm{V}^{2+}$ charge state region.

4. (a) Oxide heat of formation per $\mathrm{O}$ atom, vs parent metal work function. Note that the correlation is not a straight line as would be expected if the heat of formation varied only with metal electronegativity. (b) O vacancy formation energy in the O-rich and O-poor limits vs bulk heat of formation per $\mathrm{O}$ atom for selected oxides. Note the linear trend for O-rich limit, and the near zero values for the O-poor limit.

5. Variation of $\mathrm{O}$ vacancy formation energy with local $\mu_{\mathrm{O}}$ for $\mathrm{HfO}_{2}$ and $\mathrm{Ta}_{2} \mathrm{O}_{5}$ as examples. The scavenging metal (shown) can be used to set $\mu_{\mathrm{O}}$ and thus control the $\mathrm{V}_{\mathrm{O}}$ formation energy and $V_{O}$ concentration independently of the host oxide. This allows independent optimization of some device performance parameters.

6. (a) A model amorphous $\mathrm{Ta}_{2} \mathrm{O}_{5}$ network. (b) A relaxed $\mathrm{O}$ vacancy in a- $\mathrm{Ta}_{2} \mathrm{O}_{5}$, showing the defect orbital. Red spheres $=$ oxygens, blue spheres $=$ Ta. 

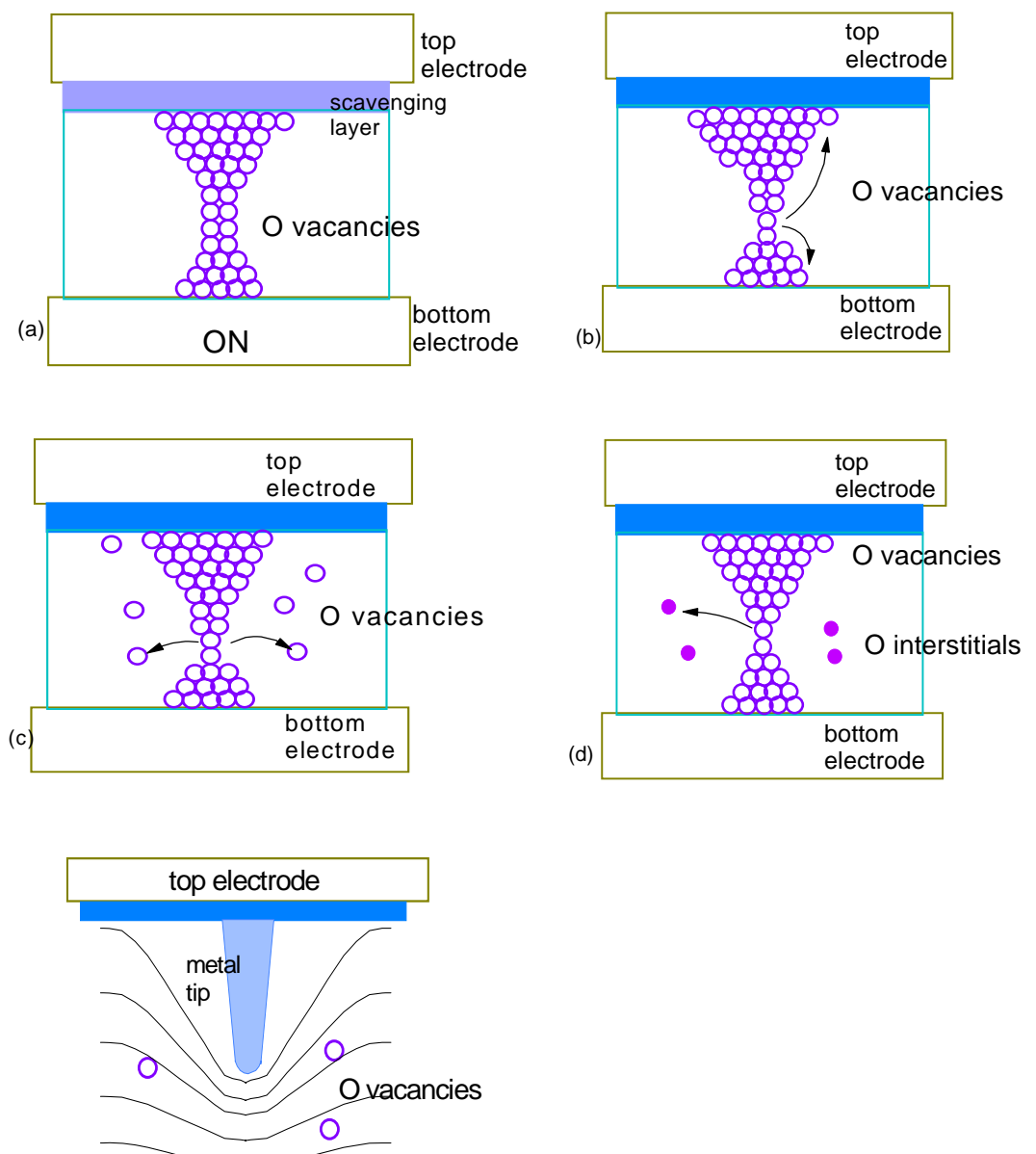

equi-potentials 0

(e)

bottom electrode

Fig. 1 

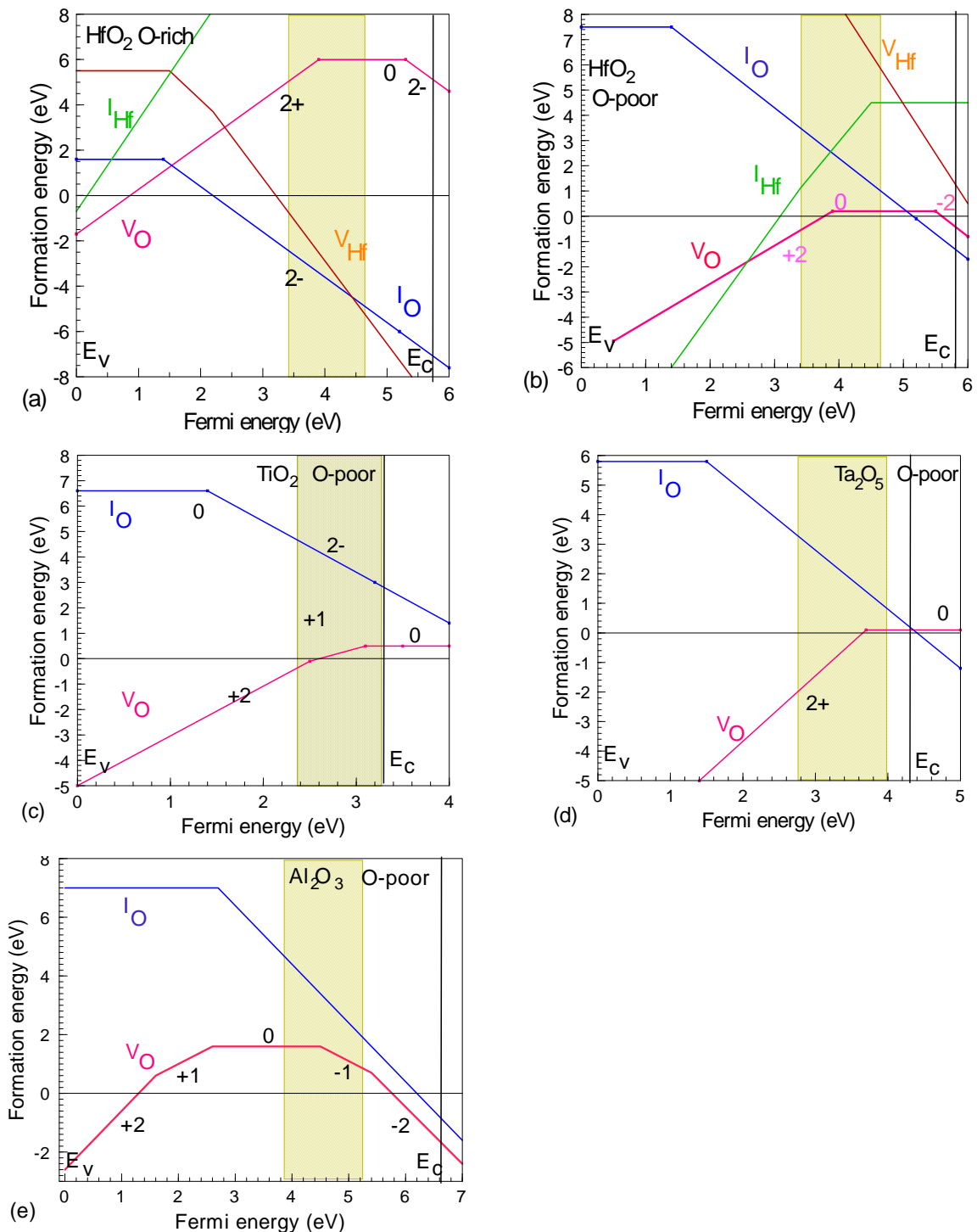

Fig 2. 


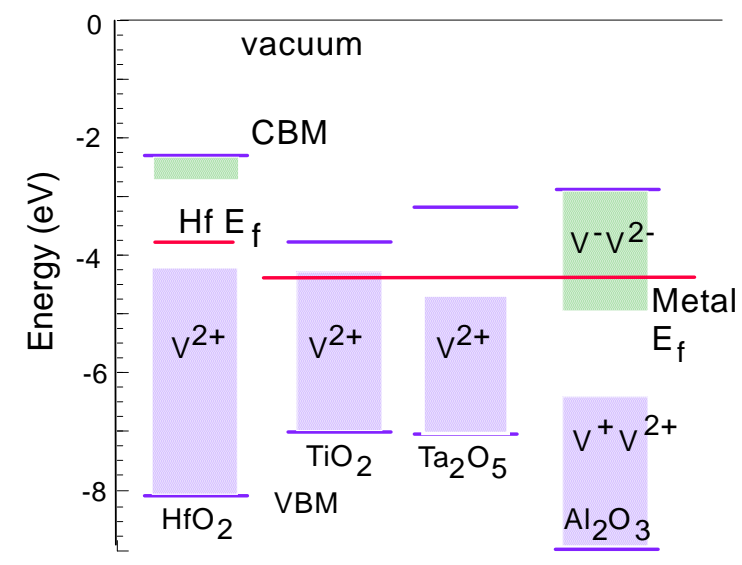

(a)

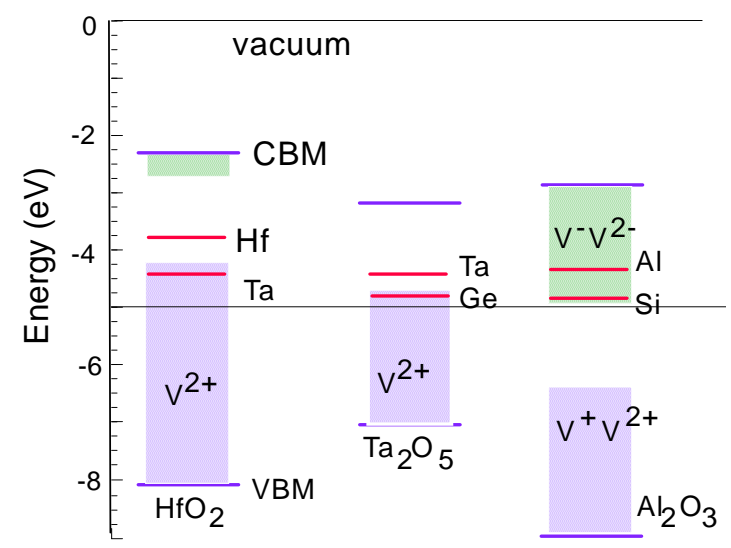

(b)

Fig. 3. 

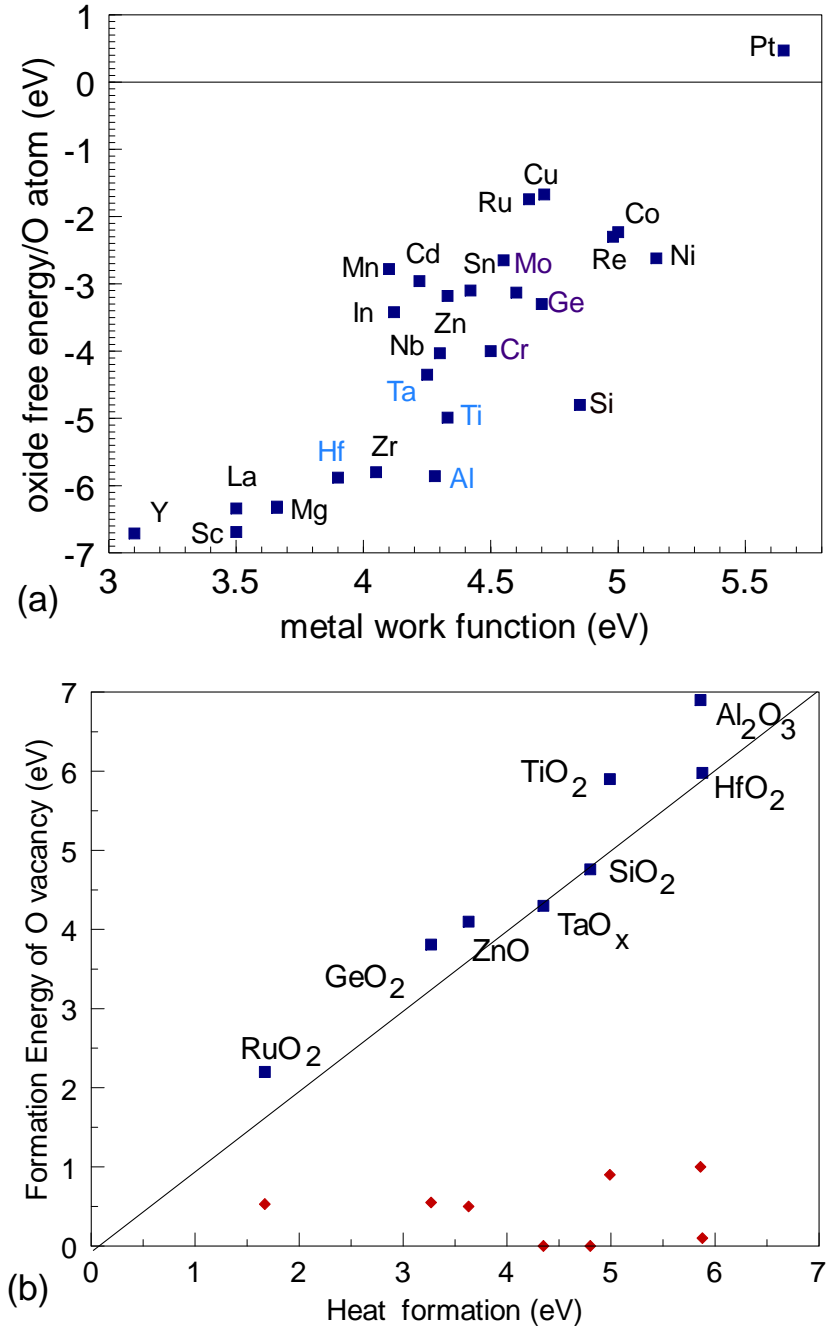

Fig 4 


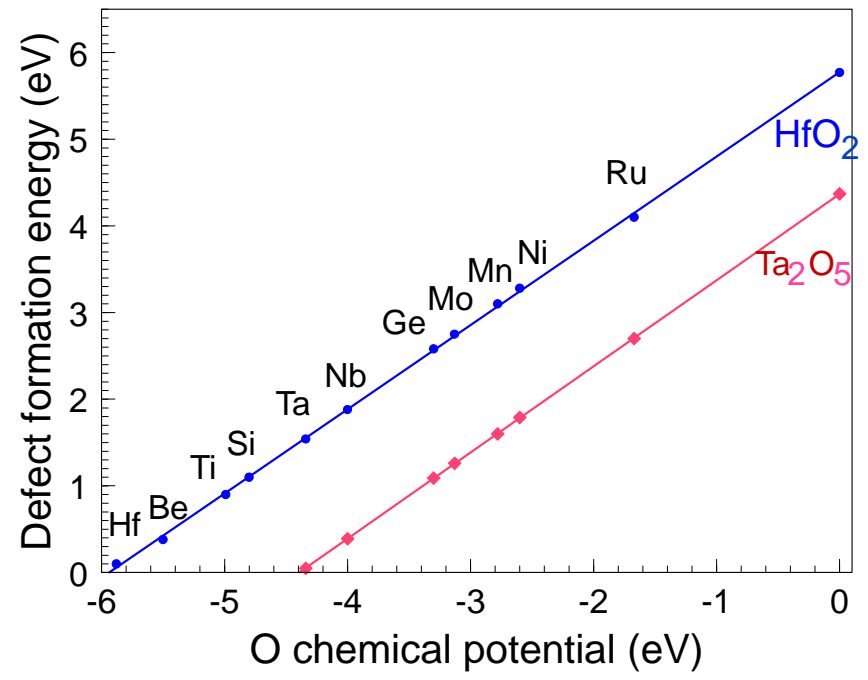

fig 5 . 

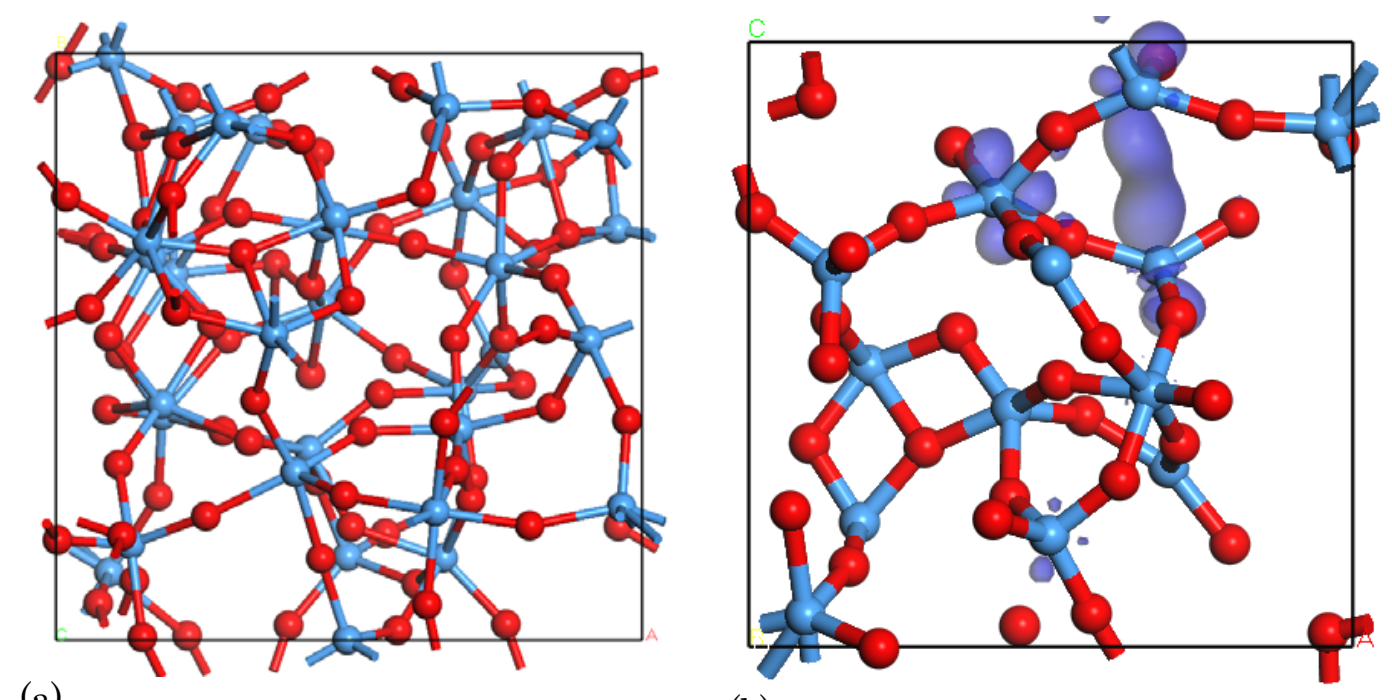

(b)

Fig. 6. 